\title{
REDESIGN OF KOZJANSKO REGIONAL PARK VISUAL IDENTITY THROUGH AN EYE TRACKING ANALYSIS OF THE CURRENT AND NEW SOLUTION
}

\author{
Elena Plahuta, Nace Pušnik \\ University of Ljubljana, Faculty of Natural Sciences and Engineering, \\ Department of Textiles, Graphic Arts and Design, Ljubljana, Slovenia
}

\begin{abstract}
Nowadays, people are increasingly more aware of natural resources which enrich and shape our living space. The Kozjansko Regional Park boasts with rich cultural and natural heritage that is worth seeing in person. The visual identity of the park greatly influences the level of visits and awareness of these natural riches. Through its visual identity the park reflects its uniqueness, strategies, and vision, thus communicating with its current and potential visitors. The purpose of this study was to investigate and analyse the existing visual identity of the park through the colour combinations and typography of the existing logo. Additional aim of the study was the redesign of the existing printed material for the Kozjansko Regional Park's Gruska cave. In the study we have developed a redesigned solution of the existing graphic materials as a part of the park's visual identity.
\end{abstract}

Key words: brand colours, eye tracking, logo design, typography, visual identity

\section{INTRODUCTION}

Slovenia is widely known for its natural beauties and plenty possibilities for enjoyment of unspoiled nature. For this reason, parks are divided into three main groups: National, Regional and Landscape parks. Triglav National park is the biggest, followed by three regional parks (Kozjansko Regional Park, Škocjan Caves Regional Park, and Notranjska Regional Park) and around 40 Landscape parks. Over the years, there have been tries of connecting all regional parks under the same graphic outlook but somehow it was difficult to design the outlook which will capture all the essential information of three parks. For this reason, every park has its own graphic outlook (Figure 1).

Kozjansko Regional Park

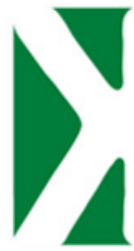

Škocjan Caves Regional Park

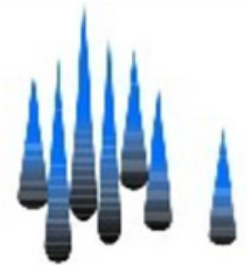

Notranjska Regional Park

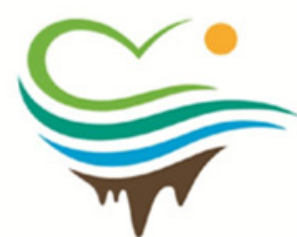

Figure 1: Visual identities of Slovenian regional parks

Our special interest was in graphic outlook of Kozjansko Regional Park. People responsible for park are trying to make it more known and for this reason they are trying to renovate its offer which pulls behind many other aspects of public communication.

Kozjansko Regional Park is positioned in eastern Slovenia. It has status of biosphere reserve and is under the UNESCO and Nature 2000 protection. Since park has rich natural and cultural inheritance, there are many possibilities for visitors to enjoy them. Here we bump into the problem of correct and appropriate advertising of different activities which are available within the park. Many activities such as hiking, cycling, Nordic walking, running, cultural events, science camps etc. should be properly advertised as part of the overall graphic image of Kozjansko Regional Park. Appropriate graphic outlook should communicate and attract visitors or random visitors. All these facts got our attention to make a research how well the existing corporate graphic identity works, what are their pros and cons and what kind of changes or adjustments could and should be made with the aim of better and more appropriate advertising (Adir et al, 2012; Airey, 2009). 


\section{METHODS}

Two different approaches were used to investigate, how graphic outlook affects people (Butina et al, 2000; Dabner et al, 2011; Feng, 2009). First approach was online survey, which was mainly based on subjective responses of participants. Second method was more objective while participants were measured with an eye tracking device Tobii X120. In both methods participants had to look at some pictures, headlines/signs, search for certain information and answer questions about the presented content (Franken et al, 2015; Georg, 2018). The main difference was of course in gathered results. Eye tracking device provided gaze plots and heat maps based on which we could see if participants were honest about their answers and what attracted them the most.

First testing was as mentioned online survey. It was sent randomly through different communication channels. Participants were of different gender and age. Beside this, our interest was also in their education degree and region of residence. We believe that education and living environment can affect results gathered this way. 55 participants $(N=55)$ have cooperated in the online survey. Data about their gender, age, education level and region of residence is shown in Table 1.

Table 1: Characteristics of online survey participants [\%]

\begin{tabular}{|c|c|c|c|c|c|c|c|c|c|c|c|c|c|c|c|c|}
\hline \multicolumn{2}{|c|}{ Gender } & \multicolumn{2}{|c|}{ Age } & \multicolumn{3}{|c|}{ Education level } & \multicolumn{10}{|c|}{ Region of residence } \\
\hline$M$ & $F$ & $15-20$ & $21-26$ & $H S E$ & UE & HPE & 1 & 2 & 3 & 4 & 5 & 6 & 7 & 8 & 9 & 10 \\
\hline 20 & 80 & 10 & 90 & 75 & 20 & 5 & 27 & 20 & 15 & 12 & 7 & 7 & 5 & 3 & 2 & 2 \\
\hline
\end{tabular}

M-male, F-female.

HSE-High School Education, UE-University Education, HPE-Higher Professional Education.

1-Savinjska, 2-Koroška, 3-Osrednjeslovenska, 4-Obalno-kraška, 5-Posavska, 6-Gorenjska, 7-Goriška, 8-Podravska, 9-Jugovzhodna, 10-Pomurska.

Second testing was performed in the laboratory conditions (Pušnik et al, 2016a; Pušnik et al, 2016b; Rayner, 1998). Environment of performed tests was in room that is equipped in line with standards suggesting optimal viewing conditions when performing tests on the screen ISO 9421 (International Organization for Standardization, 2009). As mentioned by standard, walls and ceiling should be in grey colour (RAL 7037) with specifications which are defined by ISO 3664 (International Organization for Standardization, 2008). Screen used in testing was 24-inch LCD screen (HP ZR24W) with resolution of 1920×1200 px. Similar to first testing, general data about the participants $(\mathrm{N}=55)$ was gathered at the beginning of each test and is shown in Table 2.

Table 2: Characteristics of eye tracking participants [\%]

\begin{tabular}{|c|c|c|c|c|c|c|c|c|c|c|c|c|c|c|c|c|}
\hline \multicolumn{3}{|c|}{ Gender } & \multicolumn{3}{|c|}{ Age } & \multicolumn{1}{|c|}{ Education level } & \multicolumn{1}{|c|}{ Region of residence } \\
\hline$M$ & $F$ & $15-20$ & $21-26$ & HSE & UE & HPE & 1 & 2 & 3 & 4 & 5 & 6 & 7 & 8 & 9 & 10 \\
\hline 18 & 82 & 35 & 65 & 62 & 27 & 11 & 24 & 22 & 16 & 7 & 9 & 7 & 5 & 4 & 4 & 2 \\
\hline
\end{tabular}

M-male, F-female.

HSE-High School Education, UE-University Education, HPE-Higher Professional Education.

1-Savinjska, 2-Koroška, 3-Osrednjeslovenska, 4-Obalno-kraška, 5-Posavska, 6-Gorenjska, 7-Goriška, 8-Podravska, 9-Jugovzhodna, 10-Pomurska.

We would like to stress out that either test was performed with different participants (Rayner, 2001). Final number of participants combined in both tests was 110 and every result is from different person (nobody took same or the opposite test twice). In our opinion this is important while in this way we have avoided participants' accustoming to the displayed images and questions, thus limiting factors that could negatively affect the obtained results (Repovš, 1995).

\section{RESULTS}

Through the experimental part of the study we wanted to find out, what is the basic knowledge about different natural parks in Slovenia. First question was about difference between national, regional and landscape parks. More than $50 \%$ of all participants confirmed their knowledge about difference. Next question was about number of regional parks. A little les then $50 \%$ of participants answered correct number of regional parks which is 3 . 
When asking participants about their opinion if regional parks should be presented and advertised under the same brand, more than half of participants was not sure about it. Specificity of the regions is quite big so answers to this question are probably consequence of diversity.

Our next interest was in parks visits. Since we focused on regional parks, our question was about visits of regional parks. More than 50\% of participants most often visits Škocjan Caves Regional Park. Quarter (approx. 25\%) of participants already visited Kozjansko Regional Park. 20\% of participants visited Notranjska Regional Park and around $5 \%$ have not visited any of regional parks.

Before asking participants about appropriateness of logo variations we wanted to find out what is their opinion about visual identity of regional parks. The question was if visual corporate identity affects recognizability and consequently visits of Slovenian regional parks. More than $80 \%$ of participants opinion was that good visual corporate identity is important for recognizability and people's desire to visit the parks. For this reason, we asked participants, which graphic design affects the most recognizability. Table 3 presents answers to this question.

Table 3: The most influential part of graphic design [\%]

\begin{tabular}{|c|c|c|c|c|c|c|c|c|}
\hline Logo & $\begin{array}{c}\text { Marking } \\
\text { boards }\end{array}$ & $\begin{array}{c}\text { Web } \\
\text { page }\end{array}$ & $\begin{array}{c}\text { Colour } \\
\text { selection }\end{array}$ & Leaflet & $\begin{array}{c}\text { Business } \\
\text { card }\end{array}$ & Ads & $\begin{array}{c}\text { Typeface } \\
\text { selection }\end{array}$ & $\begin{array}{c}\text { Promotional } \\
\text { vehicles }\end{array}$ \\
\hline 21 & 16 & 18 & 10 & 7 & 1 & 20 & 4 & 3 \\
\hline
\end{tabular}

\subsection{Online survey}

Six series of logos (without typeface sign) were presented to participants (including the current one which is Logo 1 in $1^{\text {st }}$ and Logo 3 in $5^{\text {th }}$ series). Logos maintained the same layout; the differences were in the colour combinations. In each series from 1 to 4 (Table 4) participants had to choose one out of five presented logos while in series 5 and 6 (Table 5) their job was to select five out of ten. Tables 4 and 5 shows the percentage distribution of participants' choices/opinion.

In the $1^{\text {st }}$ series Logo 1 was selected the most times. $57 \%$ of participants choose this version of logo. In $2^{\text {nd }}$ series again the most times selected $\log$ o was under number 1 . Logo 1 in $1^{\text {st }}$ and $2^{\text {nd }}$ series is actually inverted version (same red and green colour). When comparing $3^{\text {rd }}$ and $4^{\text {th }}$ series, the most participants choose Logo 2 (48\% in $3^{\text {rd }}$ series and $47 \%$ in $4^{\text {th }}$ series). This is somehow logical while both logos are the same; differences were made in other presented logos.

Table 4: Series of logos 1

\begin{tabular}{|c|c|c|c|c|c|}
\hline Series & Logo 1 & Logo 2 & Logo 3 & Logo 4 & Logo 5 \\
\hline \multicolumn{6}{|l|}{$1^{\text {st }}$} \\
\hline Choice [\%] & 57 & 16 & 14 & 7 & 6 \\
\hline \multicolumn{6}{|l|}{$2^{\text {nd }}$} \\
\hline Choice [\%] & 36 & 32 & 20 & 7 & 5 \\
\hline \multicolumn{6}{|l|}{$3^{\text {rd }}$} \\
\hline Choice [\%] & 5 & 48 & 23 & 21 & 3 \\
\hline \multicolumn{6}{|l|}{$4^{\text {th }}$} \\
\hline Choice [\%] & 10 & 47 & 15 & 21 & 7 \\
\hline
\end{tabular}

In $5^{\text {th }}$ and $6^{\text {th }}$ series (Table 5) participants had to choose five out of ten logos. Dispersion of results in this case is much higher. Table 5 shows undivided distribution of results (consequence of selecting five out of ten examples). Participants were more inclined to logos under the labels from 1 to 5 . Four out of five logos achieved 12 or more percent participants choice. Background colour at logos from 1 to 5 was a bit darker 
which could affect distribution of results. Similar is finding for $6^{\text {th }}$ series. Percentage distribution is higher for logos from 1 to 5 . At $6^{\text {th }}$ series, background colour of logos remained the same while smaller part of the logo (inner part of letter P) differed in colour (saturation).

Table 5: Series of logos 2

\begin{tabular}{|c|c|c|c|c|c|}
\hline Series & Logo 1 & Logo 2 & Logo 3 & Logo 4 & Logo 5 \\
\hline $5^{\text {th }}$ & & & & & \\
\hline Choice [\%] & 13 & 12 & 14 & 15 & 7 \\
\hline & Logo 6 & Logo 7 & Logo 8 & Logo 9 & Logo 10 \\
\hline Choice [\%] & 10 & 9 & 3 & 11 & 6 \\
\hline \multirow[b]{2}{*}{$6^{\text {th }}$} & Logo 1 & Logo 2 & Logo 3 & Logo 4 & Logo 5 \\
\hline & & & & & \\
\hline \multirow[t]{2}{*}{ Choice [\%] } & 15 & 11 & 13 & 15 & 6 \\
\hline & Logo 6 & Logo 7 & Logo 8 & Logo 9 & Logo 10 \\
\hline Choice [\%] & 12 & 7 & 5 & 13 & 3 \\
\hline
\end{tabular}

Next task for participants was to select typeface, which (by their opinion) fits original logo the most (original logo was presented next to typefaces). Five different typefaces (among which the currently used was included; Typeface 5) were presented to participants. Table 6 shows percentage distribution for five different typefaces.

Table 6: Series of typefaces

\begin{tabular}{|c|c|c|}
\hline Typeface & & Choice [\%] \\
\hline 1 & Kozjanski park & 26 \\
\hline 2 & Kozjanski park & 25 \\
\hline 3 & Kozjanski park & 21 \\
\hline 4 & Kozjanski park & 15 \\
\hline 5 & Kozjanski park & 13 \\
\hline
\end{tabular}

1-Eagle Lake Regular, 2-Crimson Text Italic, 3-Montserrat Light, 4-Roboto Condensed Regular, 5-Anima Normal

Participants opinion was that the most suitable for current logo is typeface Eagle Lake Regular (Typeface 1), followed by Crimson Text Italic (Typeface 2). Both typefaces got similar percentage of answers. Surprising fact is that Anima Normal (Typeface 5) which is currently in use got the lowest percentage of answers.

The last task within the online survey was to select the most optimal combination of the logo and typeface (Table 7). Difference between $1^{\text {st }}$ and $2^{\text {nd }}$ series was in the colour saturation of the logo. In $1^{\text {st }}$ series green colour was unsaturated while the $2^{\text {nd }}$ series was saturated (green colour in $2^{\text {nd }}$ series was the same as in the currently used logo). The allocation of typefaces (signs) under the logo was in all cases the same (the typeface used in the unsaturated and saturated colour combination was in the same place). Table 7 presents the percentage distribution of participants' choices/opinions. 
Table 7: Series of logos and typefaces

\begin{tabular}{|c|c|c|c|c|c|}
\hline Series & 1 & 2 & 3 & 4 & 5 \\
\hline $1^{\text {st }}$ & Kozjanski park & Kozjanski park & Kozjanski park & Kozjanski park & Kozjanski park \\
\hline Choice [\%] & 21 & 28 & 20 & 23 & 8 \\
\hline $2^{\text {nd }}$ & Kozjanski park & $\begin{array}{c}\text { Kozjanski park } \\
\text { Ko }\end{array}$ & Kozjanski park & Kozjanski park & $\underset{1}{\text { Kozjanski park }}$ \\
\hline Choice [\%] & 13 & 16 & 31 & 33 & 7 \\
\hline
\end{tabular}

1-Eagle Lake Regular, 2-Crimson Text Italic, 3-Montserrat Light, 4-Roboto Condensed Regular, 5-Anima Normal

$1^{\text {st }}$ series of logo and typeface combined shows that participants were most favourable to the logo in combination with typeface Crimson Text Italic (28\%). Second combination in $1^{\text {st }}$ series (according to percent's) was combination logo and typeface Roboto Condensed Regular (23\%). In $2^{\text {nd }}$ series logo and typeface Roboto Condensed Regular achieved highest percentage (33\%), followed by logo with typeface Montserrat Light (31\%). Interesting observation is that currently used typeface (Anima Normal) in both series did not achieve highest percentage ( $1^{\text {st }}$ series with $8 \%$ and $2^{\text {nd }}$ series with $7 \%$ ). Even though typeface Anima Normal is regular version of typeface, it has thin strokes, which could be of decisive influence of selecting/not selecting that combination.

\subsection{Eye tracking testing}

Tests with eye tracking device were performed after online survey. For this reason, we could eliminate logos, typefaces and combinations, which have not achieved the highest percentage through the online survey. Table 8 presents, what was participants choice about different variations of logo (when selecting one out of four). Compared to online survey, in this case participants had only four examples as an option. In $1^{\text {st }}$ series most participants decided that Logo 2 is the most effective while $44 \%$ of them choose it. Based on average number of fixations we can notice that this logo also attracted the most attention (average number of fixations was 5.727). Similar finding is noticed in $2^{\text {nd }}$ series; the highest percentage of participants choose Logo 2 (51\%). Similar to $1^{\text {st }}$ series, example with the highest percentage has the highest average fixation number (6.309). Winning cases of $1^{\text {st }}$ and $2^{\text {nd }}$ series are actually using the same colour combination but inverted. Similarly, the results of the $3^{\text {rd }}$ and $4^{\text {th }}$ series show highest percentage and average fixation number for Logo 2 . In $3^{\text {rd }}$ series $44 \%$ of participants choose Logo 2 (average fixation number 6.200 ) and in $4^{\text {th }}$ series $42 \%$ (average fixation umber 5.891). Comparison of heatmaps for all logos in all series shows that the maximum concentration of views is exactly in the cases described (Table 8).

Table 8: Series of logos 1 (eye tracker)

\begin{tabular}{|c|c|c|c|c|}
\hline Series & Logo 1 & Logo 2 & Logo 3 & Logo 4 \\
\hline \multicolumn{5}{|l|}{$1^{\text {st }}$} \\
\hline Fix. No. (avg.) & 3.745 & 5.727 & 4.164 & 2.055 \\
\hline Choice [\%] & 22 & 44 & 27 & 7 \\
\hline \multicolumn{5}{|l|}{$2^{\text {nd }}$} \\
\hline Fix. No. (avg.) & 3.800 & 6.309 & 4.836 & 2.582 \\
\hline Choice [\%] & 16 & 51 & 29 & 4 \\
\hline \multicolumn{5}{|l|}{$3^{\text {rd }}$} \\
\hline Fix. No. (avg.) & 2.364 & 6.200 & 4.964 & 4.218 \\
\hline Choice [\%] & 9 & 44 & 35 & 13 \\
\hline \multicolumn{5}{|l|}{$4^{\text {th }}$} \\
\hline Fix. No. (avg.) & 2.364 & 5.891 & 4.509 & 4.127 \\
\hline Choice [\%] & 11 & 42 & 36 & 11 \\
\hline
\end{tabular}


Online survey (Table 5) helped us to eliminate logos that did not meet expectations about high choice. In $5^{\text {th }}$ and $6^{\text {th }}$ series (Table 9 ) is visible what was the percentage distribution if participants have less possibilities. $5^{\text {th }}$ series shows that participants in most cases select logo $3(34 \%)$; beside this average number of fixations (5.855) and heat map distribution shows that this logo was a favourite for the participants. Similarly, to $5^{\text {th }}$ series, $6^{\text {th }}$ shows that participants choose logo 3 the most times. Again, average number of fixations (4.927) and heat map distribution is in favour of this logo.

Table 9: Series of logos 2 (eye tracker)

\begin{tabular}{|c|c|c|c|c|c|}
\hline Series & Logo 1 & Logo 2 & Logo 3 & Logo 4 & Logo 5 \\
\hline \multicolumn{6}{|l|}{$5^{\text {th }}$} \\
\hline Fix. No. (avg.) & 1.855 & 3.800 & 5.855 & 4.582 & 2.600 \\
\hline Choice [\%] & 7 & 25 & 34 & 29 & 5 \\
\hline \multicolumn{6}{|l|}{$6^{\text {th }}$} \\
\hline Fix. No. (avg.) & 2.273 & 4.164 & 4.927 & 3.564 & 3.436 \\
\hline Choice [\%] & 5 & 24 & 33 & 22 & 16 \\
\hline
\end{tabular}

When comparing how suitable certain typeface is for logo (Table 10), participants equally (with 35\%) selected two different typefaces (Crimson Text Italic and Montserrat Light). Even though distribution of percentage is the same, average number of fixations is higher at typeface Crimson Text Italic (5.563: 4.545 in favour of typeface Crimson Text Italic). For this reason, we can assume that typeface Crimson Text Italic is more convenient to be combined with the logo.

Table 10: Series of typefaces (eye tracker)

\begin{tabular}{|c|c|c|c|}
\hline Typeface & & Fix. No. (avg.) & Choice [\%] \\
\hline 1 & Kozianskipark & 3.436 & 10 \\
\hline 2 & & 5.563 & 35 \\
\hline 3 & ark & 4.545 & 35 \\
\hline 4 & KO ajwhiki park & 3.745 & 20 \\
\hline
\end{tabular}

1-Eagle Lake Regular, 2-Crimson Text Italic, 3-Montserrat Light, 4-Roboto Condensed Regular, 5-Anima Normal

Next task for participants was to choose which typeface, logo and colour combination is by their opinion more suitable. When logo with lighter green colour was presented, almost half of participants decided that typeface Crimson Text Italic suits the most (47\%). Confirming this results, average number of fixations is also the highest (7.690). When darker base of logo was presented with typefaces, participants opinion was the same (36\% decided for typeface Crimson Text Italic). Typeface Eagle Lake Regular does not lag much with $35 \%$ but average number of fixations is in favour of typeface Crimson Text Italic. 
Table 11: Series of logos and typefaces (eye tracker)

\begin{tabular}{|c|c|c|c|c|c|c|c|}
\hline \multicolumn{2}{|c|}{ Logo \& typeface 1} & Fix. No. (avg.) & Choice [\%] & \multicolumn{2}{|c|}{ Logo \& typeface 2} & Fix. No. (avg.) & Choice [\%] \\
\hline 1 & Kozjan i park & 3.582 & 18 & 1 & Ko & 3.200 & 15 \\
\hline 2 & Kozing i park & 6.200 & 13 & 2 & & 5.745 & 35 \\
\hline 3 & D. & 7.690 & 47 & 3 & & 6.672 & 36 \\
\hline 4 & Kozanski park & 4.436 & 22 & 4 & & 4.491 & 15 \\
\hline
\end{tabular}

1-Anima Normal, 2-Eagle Lake Regular, 3-Crimson Text Italic, 4-Montserrat Light.

While tendency is to make all printing materials more attractive, renovation of an existing one was involved in our experiment. Two products were graphically renewed; brochure and poster for natural science camp. Since we wanted to find out if our solutions are better, the verification of the old and renewed product was inevitable. It would not make sense for participants just to stare in old and renewed brochure, so we actually gave them task to find certain information (same in both versions). In both examples' participants were asked to find data about number of different animal species that use Kozjansko regional park as their primary biosphere environment. Heat maps of observed pages are presented in Figure 2.
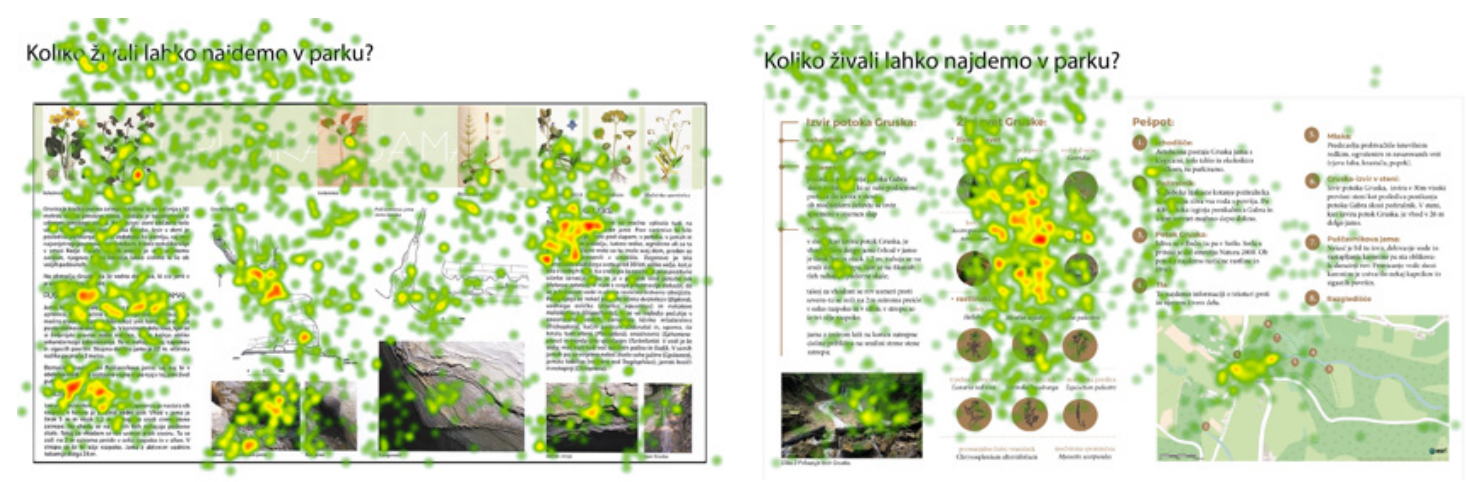

Figure 2: Example of old (left) and new (right) Kozjansko regional park brochure

Higher dispersion of fixations (combined in heatmaps) is noticed at the old brochure (Figure 2, left). Participants had difficulties (or did not find) to fixate on the part of the brochure were the data about number of species is. For this reason, number of correct answers was less then $50 \%$ (20 out of 55 participants answered correctly). When renewed version of brochure was presented to participants (Figure 2, right), we can see that main fixation area was at the part where the data about animal species is gathered. Since the data was visible and easy to find, 41 participants (out of 55) answered correctly.

Beside brochure, poster for natural science camp was renewed. Again both, old and new version of poster were presented to participants. In both cases, participants had to find data about submission deadline for camp. Old example of poster (Figure 3, left) shows two areas of participants interest. The lower area (red colour of the heat map) is the actual place where the data about submission deadline is positioned. At the renewed version of poster, fixations are gathered more together and in the upper part of the poster (Figure 3 , right). Despite the fact that concentration of participants fixations is more together at the renewed version of poster, number of correct answers was higher for old version of poster (46 out of 55 correct answers for old poster and 45 out of 55 correct answers for renewed poster). It seems that new poster was too much graphical (colour and photography use) which was somehow distractive for participants. Focus was spread around the poster and this could be reason for less correct answers in comparison to old version of poster. 

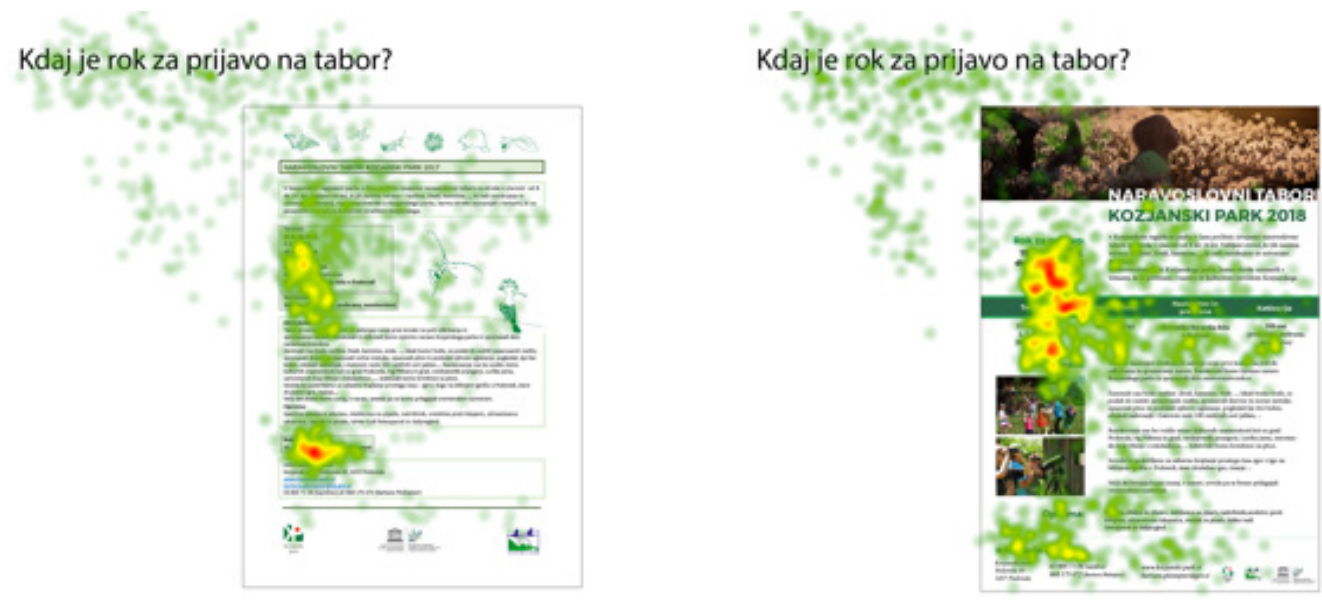

Figure 3: Example of old (left) and new (right) Kozjansko regional park poster for natural science camp

Renovation of printed matter was half-successful. If the brochure was obtained on the transparency of the data, we cannot claim same for the poster. Based on correct answers, it is welcome that brochure contains a lot of graphical material (different colours, photos, maps, etc.) while all this can be distractive if put on poster in too large amount. By changing the poster, we did not achieve a better effect on the participants. Information presented on poster should be clean and clear. For that, search of information is somehow easier.

\section{DISCUSSION}

More than $50 \%$ of participants new the difference between national, regional and landscape parks and the same number of participants new that there are three regional parks in Slovenia. Based on gathered data we can assume that participants had good general knowledge about the subject.

The ease of visiting parks is the following; most participants visited Škocjan Caves Regional Park, follows Kozjansko and Notranjsko Regional Park. Despite the fact that most participants of online survey and eye tracking testing visited at least two of mentioned parks, logos of three parks are not recognizable, more than half of participants did not recognize logos of parks they actually visited in the past.

Logo recognition was low but another interesting fact is that even though the most participants visited Škocjan Caves Regional Park, logo of mentioned park does not achieve significantly better recognition compared to the remaining two logos. In fact, the most recognized logo was Kozjansko Regional Park which can be consequence of the fact that many participants came from the area of Slovenia where the Kozjansko regional park is positioned.

Majority of participants agreed that visual image affects recognizability and visits of regional parks. The most important part of visual image by their opinion is logo. Online survey shows that a well-designed logo can create a good impression on visitors.

While testing colour combinations of logos and typefaces with online survey, deviations were small, however, the responses differed. Objective data about actual eye movement while observing certain combinations were missing. Nevertheless, analyse of data showed where are the weakness of presented logos, colour combinations and typefaces. For this reason, we could eliminate some examples and prepare examples of smaller scale for further testing. Investigation with the help of an eye tracking device guaranteed somehow more objective results.

Eye tracking testing included checking of two printed materials; old and restructured versions. The main goal of it was to rearrange data, add colours and photos which in our opinion could help to find certain information faster and with less effort. A lot of attention was paid to colour contrast of background colour and colour of typefaces. Connection of these two factors plays important role at visibility and legibility of presented information. Nevertheless, we set a limit not to use too many different colours and typefaces. Every printed matter was based on one dominant colour. Text data was emphasized by thoughtful introduction of colours, layout and size.

Brochure of Gruska cave had to be completely revised while the old version included some information which are old and had no special meaning for visitors. Text was somehow enriched with photos and 
associated signatures which represented the combination for more favourable reading. Further extension included pictograms and maps.

Visibility of headlines and photo signatures was achieved with the introduction of brown colour on a white background; sans serif typeface was combined with that. Reverse colour combination was used on first and last page of brochure where background colour was dark brown and typeface colour was white. On these two pages photo of Gruska cave was used including two rectangles in dark brown colour. We have avoided placing text on a photo while this could have negative effect on contrast between background and typeface. Consequently, bad contrast could affect visibility and legibility; for this reason, text was placed into two rectangles. All this resulted in greater contrast and better visibility. Headlines were aligned centrally which represent universal alignment; words are evenly distant from one another.

Beside brochure, poster for natural science camp was changed. Compared to the poster which is in use, we added photos to the new one. Reason for this was to prove, how important role photo can have for certain products and that it can help get things closer to people. Central element of posters was photo of a girl in the field of dandelion flowers. The photo is also the part of main headline which is in white colour. This combination establishes enough of contrast between background (photo) and typeface. The main data was stressed with addition of green background (typeface remained in white colour). Area with registration information was divided from the rest of the information with dashed line.

Results gathered with an eye tracking device showed that redesign of printed materials were correct. Main role was in appropriate contrast between background and typeface colour. Transparency has been established with different hierarchy (compared to old printed materials). Another positive thing of redesign was introduction of photos. Especially testing of brochure showed that all implemented factors helped participants to find certain information faster and with less effort (this is concluded based on fixations and heat maps area coverage). Combination of text and photos, splitting a longer text into paragraphs, hierarchy and emphasis in the text has positive influence on attractiveness and sense of organization in printed materials.

Less successful was redesign of poster for natural science camp. There was small difference (answer correctness, number of fixations, heat maps distribution) between the poster which is in use and the poster we redesigned. Attractiveness of new poster is undoubtedly in good visibility of green letters on the white background. Opposite our opinion is that the frames which are in use at the older version of poster attract participants in the same amount as green letters of new poster, even though use of frames is more suggested for short texts and headlines.

Four typeface which turn out as the best in the online survey were tested with eye tracking device; calligraphic typeface Eagle Lake Regular, Serif Typefaces Crimson Text Italic and Anima Normal, sans serif typeface Montserrat Light. These typefaces differ in typographic style, thickness of strokes, use of serifs, etc. When observing results (heatmaps), it is noticeable that participants focused the most on letters $\mathrm{j}$ and z. We assume that these two letters were defining ones of attractiveness decision. Typeface which is in use (Anima Normal) was actually selected less times compared to other typefaces. We assume that reason for this can be in small contrast between typeface strokes (letters have extremely thin strokes) and background colour.

Testing logo and typeface together was compiled with four typefaces that were chosen the most times in online survey. Most of participants attention was the highest on the word Kozjanski (part of sign Kozjanski park). Logo colour combination did not have important role in this case which is noticeable through heatmaps. The latter were mostly spread across sign and not logo. Number of fixations was proportionate to the correctness of the answers; more fixations, more correct answers. Since sign was placed under logo, interesting further research could be how different placement of logo and sign could affect results.

\section{CONCLUSIONS}

The effectiveness of the redesigned solution was verified using the methods of online survey and eye tracking testing. The experiment included testing of the current visual identity, colour combinations of the logo and corresponding typography (with and without the logo). Through online survey, we acquired data on the general knowledge of people about regional parks and, in addition, subjective responses on colour combinations of logos and the corresponding typography. We have concluded that regional parks are well known and visited. The results of colour combinations of logos and the corresponding typography did not give us all the data we wanted and needed. Therefore, we made the check by an objective eye tracking method. The results from an eye tracking analysis showed some positive results for the redesigned visual identity and printed material. When testing typefaces without logo, participant's selection was based on 
letters $\mathrm{j}$ and $\mathrm{z}$ (since those two letters draw high attention and had the biggest heat map area). The results of testing colour combination with the various typography showed that the colour of the logo does not influence the typography selection.

\section{REFERENCES}

[1] Adir, V., Adir, G., Pascu, N.-E.: "How to design logo", Procedia - Social and Behavioral Sciences 122, 140-144, 2014. doi:10.1016/j.sbspro.2014.01.1316.

[2] Airey, D.: "Logo design love: A guide to creating iconic brand identities", (New Riders, Berkeley, 2009), page 219.

[3] Butina, M.: "Mala likovna teorija", (Debora, Ljubljana, 2000), page 174.

[4] Dabner, D., Calvert, S., Casey, A.: "Grafično oblikovanje: Priročnik za grafične oblikovalce tiskanih, digitalnih in večpredstavnostnih medijev", (Tehniška založba Slovenije, Ljubljana, 2011), page 192.

[5] Feng, G.: "Time course and hazard function: a distributional analysis of fixation duration in reading", Journal of Eye Movement Research 3 (2), 1-23, 2009. doi: 10.16910/jemr.3.2.3.

[6] Franken, G., Podlesek, A., Možina, K.: "Eye-tracking study of reading speed from LCD displays: influence of type style and type size", Journal of Eye Movement Research 35 (6), 442-451, 2015. doi: 10.16910/jemr.8.1.3.

[7] Georg, J., Color Theory 101, URL https://www.sitepoint.com/color-theory-101-2/ (last request: 2018-02-25).

[8] Pušnik, N., Možina, K., Podlesek, A.: "Effect of typeface, letter case and position on recognition of short words presented on-screen", Behaviour \& Information Technology 8 (1), 1-8, 2016a. doi: 10.1080/0144929X.2016.1158318.

[9] Pušnik, N., Podlesek, A., Možina, K.: "Typeface comparison - does the x-height of lower-case letters increased to the size of upper-case letters speed up recognition?" International Journal of Industrial Ergonomics 54, 164-169, 2016b. doi: 10.1016/j.ergon.2016.06.002.

[10] Rayner, K.: "Eye movements in reading and information processing: 20 years of research", Psychological Bulletin 124 (3), 372-422, 1998.

[11] International Organization for Standardization, ISO 9241-300:2008 - Ergonomics of human-system interaction-part 305: Optical laboratory test methods for electronic visual display, GENEVA: International Organization for Standardization, 2009.

[12] International Organization for Standardization, ISO 3664:2009 - Graphic technology and photography: Viewing conditions, GENEVA: International Organization for Standardization, 2008.

[13] Rayner, K., Foorman, B., Perfetti, C., Pesetsky, D., Seidenberg, M.: "How psychological science informs the teaching of reading", Psychological science 2 (2), 31-74, 2001. doi: 10.1111/15291006.00004.

[14] Repovš, J.: "Kako nastaja in deluje učinkovita, tržno usmerjena celostna grafična podoba kot del simbolnega identitetnega Sistema", (Studi marketing, Ljubljana, 1995), page 191.

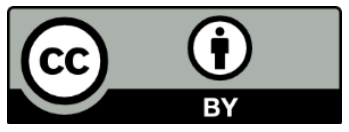

(C) 2018 Authors. Published by the University of Novi Sad, Faculty of Technical Sciences, Department of Graphic Engineering and Design. This article is an open access article distributed under the terms and conditions of the Creative Commons Attribution license 3.0 Serbia (http://creativecommons.org/licenses/by/3.0/rs/). 